\title{
Reduced Haematopoietic Output in Automobile Mechanics and Sprayers with Chronic Exposure to Petrochemicals: A Case-Control Study in Cape Coast, Ghana
}

\author{
Patrick Adu $\mathbb{D}^{1},{ }^{1}$ Richard Pobee, ${ }^{1}$ Aaron Awuah, ${ }^{1}$ Paul B. Asiamah, \\ Festus Amoani, ${ }^{1}$ and Sampson Gyabaa ${ }^{2}$ \\ ${ }^{1}$ Medical Laboratory Science Department, School of Allied Health Sciences, University of Cape Coast, Cape Coast, Ghana \\ ${ }^{2}$ Medical Laboratory Department, Ewim Polyclinic, Cape Coast, Ghana \\ Correspondence should be addressed to Patrick Adu; patrick.adu@ucc.edu.gh
}

Received 8 September 2017; Accepted 19 February 2018; Published 26 March 2018

Academic Editor: Mynepalli K. C. Sridhar

Copyright ( $) 2018$ Patrick Adu et al. This is an open access article distributed under the Creative Commons Attribution License, which permits unrestricted use, distribution, and reproduction in any medium, provided the original work is properly cited.

Background. Automobile mechanics and sprayers are at a higher risk of exposure to hazardous chemicals such as polycyclic aromatic hydrocarbons and heavy metals which may cause adverse health outcomes. This study aimed to use reticulocyte count as an indirect measure of the haematological output in automobile mechanics and sprayers in the Cape Coast Metropolis, Ghana. Method. This cross-sectional study recruited 130 participants: 90 cases (57 automobile mechanics and 33 automobile sprayers) and 40 controls (nonautomobile workers). Venous blood samples were drawn from the participants and examined for full blood count and absolute reticulocyte count. Semi-structured questionnaire was used to collect demographic and occupational safety information from participants. Results. $75.6 \%$ of cases had never received occupational safety training. Whereas $35.1 \%$ of automobile mechanics routinely siphoned fuel, $36.4 \%$ of automobile sprayers never used nose masks in the discharge of their duties. Controls had significantly higher WBC counts compared to mechanics $(p=0.0001 ; 5.04 \pm 1.7$ versus $3.81 \pm 1.1)$, or sprayers $(p=0.0004$; $5.04 \pm 1.7$ versus $3.74 \pm 0.9$ ). Lymphocyte, monocyte, and platelet counts were also significantly higher in controls compared to cases. Whereas RBC counts were significantly higher in controls compared to automobile mechanics ( 4.85 versus $4.66 ; p=0.034)$, haemoglobin levels were significantly higher in automobile sprayers compared to controls (15.13 versus $14.1 \mathrm{~g} / \mathrm{dl} ; p=0.0126$ ). Absolute reticulocyte count was significantly higher in controls compared to cases $\left[p<0.0001 ;(56.88 \pm 32.14) \times 10^{9} / \mathrm{L}\right.$ (controls) versus $(25.31 \pm 15.75) \times 10^{9} / \mathrm{L}$ (sprayers) or $(33.27 \pm 24.42) \times 10^{9} / \mathrm{L}$ (mechanics) $]$. Among the cases however, only RBC counts were significantly lower in automobile mechanics compared to automobile sprayers ( $p=0.0088 ; 4.66 \pm 0.4$ versus $4.85 \pm 0.5$ ). Conclusion . It was evident that both automobile mechanics and sprayers had significantly reduced haematopoietic output. Occupational safety training is not given priority and must be addressed.

\section{Introduction}

Exposure to aliphatic and aromatic hydrocarbons has been noted to be deleterious to the health of humankind [1]. As these chemicals are highly volatile and can subsequently be inhaled and/or absorbed through the skin, the potential for these to cause harm may be compounded in regions with high ambient temperature like Ghana. Petrochemicals which also contain some of these aromatic compounds as well as heavy metals consisting of lead, cadmium, chromium, copper, nickel, and vanadium may thus cause adverse health outcomes if exposure to these is not controlled [2].

Certain occupations such as automobile mechanics and sprayers are prone to immediate exposure to these hazardous chemicals through either inhalation, dermal exposure, or ingestion [3]. Their occupational exposure could range from routine transportation, distribution, inhalation of vehicle exhaust fumes, accidental spills, improper handling, and use of petroleum products to leaching of petroleum hydrocarbons [4]. Whereas automobile mechanics may intentionally 
siphon fuel with their mouth as they try to start the ignition [2], automobile sprayers may indirectly inhale these hazardous chemicals (even with the use of nose masks) when applying a coat (paint, ink, and varnish) unto car surface [5].

Exposure to these aromatic compounds and heavy metals may suppress the bone marrow's activity leading to ineffective hematopoiesis [6]. Heavy metals are noted to affect the haematopoietic system through the inhibition of haemoglobin synthesis by suppressing various key enzymes involved in the heme synthesis pathway and thus lead to reduced life-span of erythrocytes [7]. These aromatic chemicals have been shown to bind to bone marrow DNA leading to chromosomal abnormality [8]. Thus, chronic exposure to these aromatic compounds due to chronic inhalation may lead to undesirable consequence on the haematopoietic system in humans [9]. Although automechanics and automobile sprayers abound in Ghana, there is paucity of data regarding how their routine occupational practices impact their overall health. This study therefore sought to investigate whether the chronic exposure of these automobile workers adversely affected their haematological output. The bone marrow suppressive activity of these aromatic compounds was assessed indirectly through the reticulocyte count and reticulocyte index, which measures the red cell output from the bone marrow [10].

\section{Materials and Methods}

2.1. Sampling Sites. This case-control study recruited 130 participants: 90 cases [automobile mechanics (57) and automobile sprayers (33)] and 40 controls at Siwdo in the Cape Coast Metropolis, Ghana. The Siwdo automobile workshop is the largest in the Cape Coast Metropolis. The automobile mechanics included diesel-engine mechanics, motor trucks mechanics, engine repair mechanics, differential and brakes repairers, general automobile-service-station mechanics, workshop heads, and apprentices. A simple convenience sampling technique was employed where all consecutive individuals who gave informed consent were recruited for the study. Questionnaires were also used to collect sociodemographic data and working history of each participant.

2.2. Sample Collection and Analysis. About 3-4 mls venous blood was taken into a vacutainer containing $\mathrm{K}_{2}$ EDTA anticoagulant. Samples were analyzed using automated haematological analyzer (URIT-3000 Plus, China). New methylene blue (NMB) was used to supravitally stain participants' blood samples, after which thin blood film was prepared and used to estimate the reticulocyte counts in accordance with previously published protocols [11]. Microscopically, reticulocytes were recognized by the cytoplasmic presence of NMB-stained ribosomal RNA [11, 12] while counting 1000 red cells.

The percentage of reticulocytes was calculated according to the following formula:

$$
\begin{aligned}
& \text { Reticulocyte count }(\%) \\
& \quad=\frac{\text { number of reticulocytes }}{\text { number of red cells }(1000)} \times 100 \% \text {. }
\end{aligned}
$$

Absolute reticulocyte count is a calculated index using the values generated from the reticulocyte count percentage and RBC count from the full blood count. Therefore, the absolute reticulocyte count was calculated for all participants using the following formula:

$$
\begin{aligned}
& \text { Absolute reticulocyte count } \\
& =\text { Reticulocyte count }(\%) \times \text { RBC count. }
\end{aligned}
$$

See [12].

2.3. Statistical Analysis. GraphPad Prism version 6.0 (GraphPad Software, USA) was used for the data analysis. Data were analyzed for normality using D'Agostino-Pearson omnibus normality test, after which appropriate statistical tests were selected to compare variables. Questionnaires were entered in Microsoft Excel 2010.

\section{Results}

The demographic characteristics of the participants are presented in Table 1. All the participants were males and were mostly in the age group 20-30 years [85\% controls versus $66.6 \%$ mechanics versus $91.8 \%$ sprayers]. A significantly higher proportion of the cases frequently experienced headaches for which they took various analgesic formulations $[p=0.0035 ; 27.5 \%$ controls versus $61.4 \%$ mechanics versus $54.5 \%$ sprayers]. Also, significantly higher proportions of cases had no knowledge on health implications of the frequent handling of petrochemicals and petroleum products [ $p<0.0001 ; 70.2 \%$ mechanics versus $45.5 \%$ sprayers versus $15 \%$ controls]. Most of the cases did not use any safety measure in the discharge of their daily duties $(74.7 \%$ mechanics versus $78.8 \%$ sprayers).

The risky occupational-related behavior of the automobile workers is presented in Table 2. A significant proportion of the automobile workers had not received any training on occupational safety ( $75.6 \%$ no versus $24.4 \%$ yes; $p<0.001)$. Also, whereas $35.1 \%$ of mechanics regularly siphoned fuel in the discharge of their duties, $36.4 \%$ of sprayers never used nose mask in their discharge of their duties.

The haematological profiles of the study participants are summarized in Table 3. Mechanics had significantly lower RBC count compared to controls $(p=0.0354)$. Sprayers also had significantly higher haemoglobin levels compared to controls $[p=0.0126 ; 15.13$ (sprayers) versus $14.1 \mathrm{~g} / \mathrm{dl}$ (controls)]. However, whereas the $\mathrm{MCH}$ and $\mathrm{MCHC}$ were all significantly increased in cases compared to controls, the RDW was significantly reduced in cases compared to controls $(p<0.0001$ in each case). Additionally, the total WBC counts $[p=0.0001$ (controls versus mechanics), $p=0.0004$ (controls versus sprayers)], absolute lymphocyte count $[p<0.0001$ (control versus mechanics), $p=0.0004$ (controls versus sprayers)], and MID cell count $[p<0.0001$ (control versus mechanics), $p<0.0001$ (controls versus sprayers)] were significantly reduced in cases compared to controls. Moreover, platelet counts were significantly reduced in both mechanics $(p=$ $0.0006)$ and sprayers $(p=0.0004)$ compared to controls. 
TABLE 1: Demographic characteristics of study population.

\begin{tabular}{|c|c|c|c|c|}
\hline Variable & Controls (40) N (\%) & Mechanics (57) N (\%) & Sprayers (33) N (\%) & $p$ value \\
\hline \multicolumn{5}{|l|}{ Age (yrs) } \\
\hline$\leq 19$ & $5(12.5)$ & $5(8.8)$ & $3(9.1)$ & \\
\hline $20-39$ & $34(85)$ & $38(66.6)$ & $27(91.8)$ & \\
\hline $40-59$ & $1(2.5)$ & $14(24.6)$ & $3(9.1)$ & \\
\hline \multicolumn{5}{|l|}{ Gender } \\
\hline Male & $40(100)$ & $57(100)$ & $33(100)$ & \\
\hline Female & $\mathrm{n} / \mathrm{a}$ & $\mathrm{n} / \mathrm{a}$ & $\mathrm{n} / \mathrm{a}$ & \\
\hline \multicolumn{5}{|c|}{ General symptoms Headache } \\
\hline Yes & $11(27.5)$ & $35(61.4)$ & $18(54.5)$ & \multirow{2}{*}{0.0035} \\
\hline No & $29(72.5)$ & $22(38.6)$ & $15(45.5)$ & \\
\hline \multicolumn{5}{|c|}{ Work Experience (yrs) } \\
\hline$<10$ & $\mathrm{n} / \mathrm{a}$ & $36(63.2)$ & $23(69.7)$ & \\
\hline $10-20$ & $\mathrm{n} / \mathrm{a}$ & $14(24.6)$ & $7(21.2)$ & \\
\hline$>20$ & $\mathrm{n} / \mathrm{a}$ & $7(12.2)$ & $3(9.1)$ & \\
\hline \multicolumn{5}{|c|}{$\begin{array}{l}\text { Knowledge on any health risk of } \\
\text { petrochemicals }\end{array}$} \\
\hline Yes & $34(85)$ & $17(29.8)$ & $18(54.5)$ & \multirow[t]{2}{*}{$<0.0001$} \\
\hline No & $6(15)$ & $40(70.2)$ & $15(45.5)$ & \\
\hline
\end{tabular}

Significant $p<0.05$; chi-square $(z)$ test value; percent out of total; confidence interval $95 \%$ CI.

TABLE 2: Occupational safety awareness of participants.

\begin{tabular}{lccc}
\hline Variable & $\begin{array}{c}\text { Yes } \\
N(\%)\end{array}$ & $\begin{array}{c}\text { No } \\
\text { (\%) }\end{array}$ & $p$ value \\
\hline $\begin{array}{l}\text { Have you ever received } \\
\text { occupational safety training? }\end{array}$ & $22(24.4)$ & $68(75.6)$ & $<\mathbf{0 . 0 0 1}$ \\
$N=90$ & $20(35.1)$ & $37(64.9)$ & $\mathbf{0 . 0 2 4}$ \\
\hline $\begin{array}{l}\text { Do you siphon fuel with your } \\
\text { mouth? (mechanics only; }\end{array}$ & $21(63.6)$ & $12(36.4)$ & $\mathbf{0 . 0 4 6}$ \\
$\begin{array}{l}\text { Do 57) } \\
\text { Do you ever wear nose mask? }\end{array}$ & & \\
\hline
\end{tabular}

Among the cases however, only RBC count was significantly higher in sprayers compared to mechanics $(p=$ 0.0088 , Supplementary Table S1). Additionally, the haematological variables did not differ with respect to years at work in any of the automobile workers (S2 and S3).

To understand how the occupational exposure impacted the haematopoietic output, the \% reticulocyte count and absolute reticulocyte counts were also compared between cases and controls (Figure 1). The \% reticulocyte counts were significantly higher in controls compared to cases [Figure 1(a); $p<0.0001$ (controls versus mechanics), or $p<$ 0.0001 (controls versus sprayers)]. In addition, the absolute reticulocyte counts were significantly higher in cases compared to controls [Figure 1(b); $p<0.0001$ (controls versus mechanics), $p<0.0001$ (controls versus sprayers)].

\section{Discussion}

Chronic exposure to petrochemicals may adversely impact haematopoiesis as these contain heavy metals that may be inhibitory to enzymes crucial in blood cell formation [7]. In this study, we sought to investigate the impact of chronic exposure of petroleum products on haematopoietic output in automechanics and automobile sprayers using reticulocyte count as indirect measure of bone marrow erythropoietic output. We found significantly reduced haematopoietic output in automechanics and automobile sprayers as evidenced by generally reduced haematopoietic profiles as well as significantly reduced reticulocyte counts suggesting that exposure to these chemicals may be a potential cause of these adverse haematopoietic functions.

Previously, Aleemuddin et al. suggested that exposure to the heavy metals in aromatic compounds may lead to ineffective erythropoiesis as a consequence of its suppressive activity on the bone marrow [6]. Another cross-sectional study in Pakistan also recorded similar significant reductions in haemoglobin and RBC counts among automobile mechanics and automobile sprayers compared to controls [13]. Although our study did not estimate the levels of these heavy metals in our study participants, our findings are indicative of the fact that the bone marrow activity is negatively affected by exposure to these petrochemicals. Interestingly, significantly higher proportion of the automobile workers were oblivious of the dangers/health implications of the petrochemicals and other products they use in the discharge of their duties. This is in spite of the established role of petrochemicals 
TABLE 3: Mean hematological parameters among controls and cases.

\begin{tabular}{|c|c|c|c|c|c|}
\hline Parameters & $\begin{array}{l}\text { Controls } \\
n=(40)\end{array}$ & $\begin{array}{c}\text { Mechanics (M) } \\
n=(57)\end{array}$ & $\begin{array}{c}\text { Sprayers (S) } \\
n=(33)\end{array}$ & $p^{*}$ & $p^{* *}$ \\
\hline $\mathrm{RBC}\left(10^{12} / \mathrm{L}\right)$ & $4.85 \pm 0.6$ & $4.66 \pm 0.4$ & $4.85 \pm 0.5$ & 0.0354 & $>0.9999$ \\
\hline HGB (g/dL) & $14.10 \pm 1.6$ & $14.65 \pm 1.4$ & $15.13 \pm 1.4$ & 0.2659 & 0.0126 \\
\hline НСТ\% & $40.90 \pm 5.5$ & $39.86 \pm 3.8$ & $41.08 \pm 4.2$ & 0.1038 & $>0.9999$ \\
\hline MCV (fL) & $83.80 \pm 5.9$ & $85.63 \pm 5.6$ & $84.91 \pm 6.8$ & 0.1030 & 0.6716 \\
\hline $\mathrm{MCH}(\mathrm{pg})$ & $28.23 \pm 2.6$ & $31.44 \pm 2.3$ & $30.67 \pm 3.9$ & $<0.0001$ & $<0.0001$ \\
\hline MCHC (g/dL) & $34.01 \pm 0.7$ & $36.61 \pm 1.4$ & $36.79 \pm 1.2$ & $<0.0001$ & $<0.0001$ \\
\hline RDW-SD & $50.21 \pm 4.1$ & $31.33 \pm 2.6$ & $30.32 \pm 3.1$ & $<0.0001$ & $<0.0001$ \\
\hline WBC $\left(10^{9} / \mathrm{L}\right)$ & $5.04 \pm 1.7$ & $3.81 \pm 1.1$ & $3.74 \pm 0.9$ & 0.0001 & 0.0004 \\
\hline GRAN \# $\left(10^{9} / \mathrm{L}\right)$ & $1.76 \pm 0.9$ & $1.66 \pm 0.7$ & $1.54 \pm 0.5$ & 0.8028 & 0.5187 \\
\hline LYM \# $\left(10^{9} / \mathrm{L}\right)$ & $2.56 \pm 0.7$ & $1.94 \pm 0.6$ & $1.99 \pm 0.6$ & $<0.0001$ & 0.0004 \\
\hline MID \# $\left(10^{9} / \mathrm{L}\right)$ & $0.36 \pm 0.16$ & $0.23 \pm 0.03$ & $0.224 \pm 0.08$ & $<0.0001$ & $<0.0001$ \\
\hline $\operatorname{PLT}\left(10^{9} / \mathrm{L}\right)$ & $253.1 \pm 63.8$ & $210.8 \pm 55.1$ & $204.2 \pm 48.9$ & 0.0006 & 0.0004 \\
\hline MPV (fL) & $10.78 \pm 0.93$ & $8.77 \pm 0.843$ & $8.82 \pm 0.871$ & $<0.0001$ & $<0.0001$ \\
\hline
\end{tabular}

ANOVA; Dunn's multiple comparison; $p^{*}$ : control verses mechanics $(\mathrm{M}) ; p^{* *}$ : control verses sprayers $(\mathrm{S})$; results showing mean \pm standard deviation at $95 \%$ CI confidence interval, significant at $p<0.05$; GRAN: granulocytes (neutrophils, eosinophils); LYM: lymphocytes; MID: monocytes.

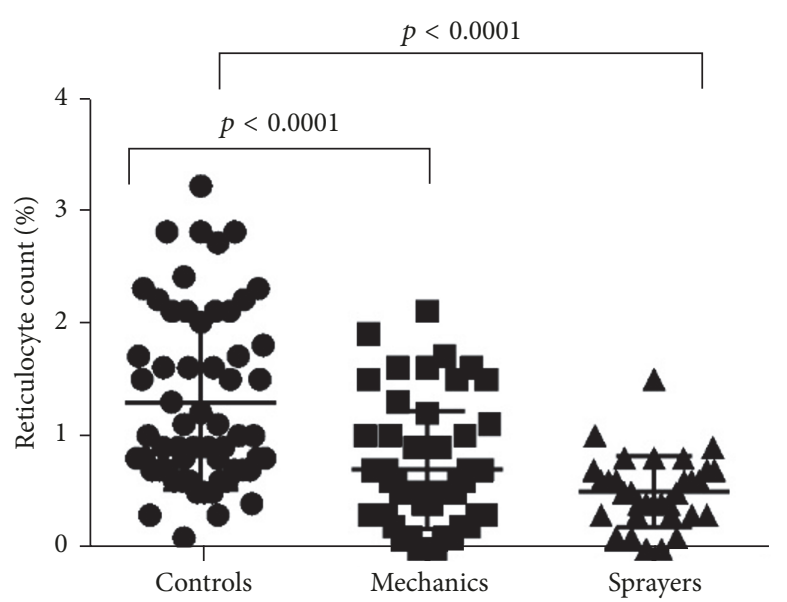

(a)

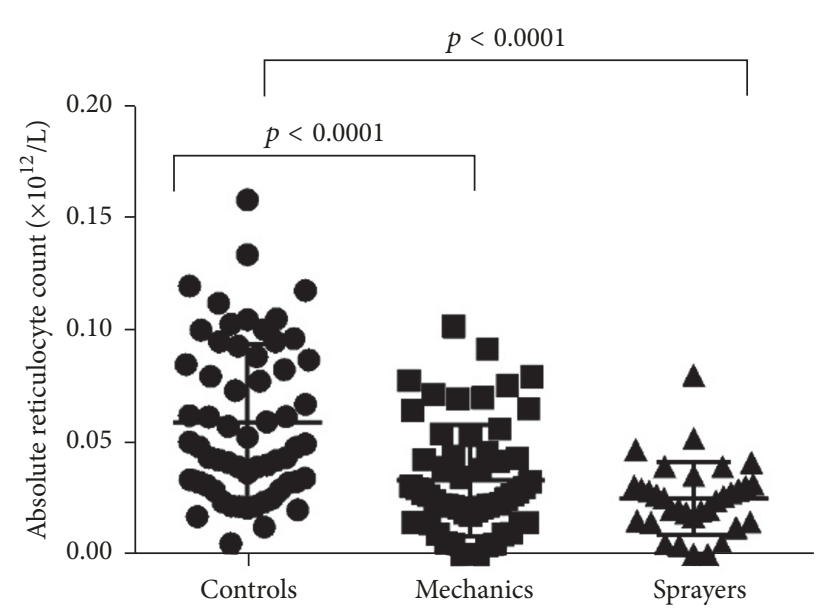

(b)

FIGURE 1: Mean absolute reticulocyte counts of cases (mechanics and sprayers) and controls. Mean absolute reticulocyte count of automobile sprayers and mechanics (cases) as against control group at $p<0.05$ using ANOVA, Kruskal-Wallis, and Dunn's multiple comparison test.

in suppressing bone marrow activity as well as cause of leukaemia $[14,15]$. It is worth noting that majority of our cases complained of frequent work-related headache and body pains for which they regularly took over-the-counter analgesics. Chronic ingestion of these analgesics has also been previously found to cause reduced lymphocyte and neutrophil count [16].

Although some of the findings in the Kamal and Malik [13] study in Pakistan like significantly reduced RBC counts agreed with the findings in this study, the critical findings like significantly increased WBC counts, MCV, and PCV in automobile sprayers compared to controls were at variance with the major findings presented herein. This could be attributed to the fact that majority of the participants in that study were smokers as smoking has been shown to cause increased levels of most haematological parameters. None of the participants in our study responded in the affirmative to smoking. Another study in Nigeria that recruited fuel attendants also reported significantly elevated WBC, granulocytes, lymphocytes, and monocytes in fuel attendants compared to controls [17]. Although the findings presented in this study are at variance with that report [17], it is a feasible supposition that the levels of exposure of automobile mechanics and sprayers to petrochemicals may be higher compared to the fuel attendants. This may be partly responsible for the differing haematological profiles in these two populations. Others that adopted animal model experimentation also reported dose-dependent reduction of haematocrit and haemoglobin concentration in relation to time of exposure [18]. However, among our automobile workers, we could not detect any trend of significant changes in haematopoietic profile with years of work. 
It is interesting to note that our cases had significantly reduced red cell distribution width (RDW) compared to our controls. Previous prospective studies as well as meta-analysis have suggested that high RDW was associated with increased risk of cardiovascular disease [19-21]. Although this study did not assess cardiovascular risk of the participants, it is possible that the physical demands of the work of automechanics might offer some protection against adverse cardiovascular effects. As RDW estimates RBC variability that may be increased in reticulocytosis, the significantly reduced reticulocyte counts in our cases could as well have resulted in low RDW. This reduced RDW in our cases should therefore be interpreted in the light of the significantly reduced reticulocyte count. As reticulocyte counts are indirect estimate of the bone marrow haematopoietic/erythropoietic output, it is fairly reasonable to suppose that the chronic exposures of these automobile workers to these petrochemical reagents may have adversely impacted haematopoiesis. Exposure to these aromatic compounds and heavy metals may suppress the bone marrow's activity leading to ineffective hematopoiesis [6] and consequently reduced reticulocyte count. Moreover, judging from the significantly reduced reticulocyte counts in our cases, the apparently normal red cell count and haemoglobin concentration in our cases might have been pseudo as a result of dehydration on the part of our cases. In spite of the high ambient temperature in Ghana, our cases reported taking $\leq 1.5 \mathrm{~L}$ of water during each working day. As plasma is about $70 \%$ water, this low fluid intake might have artificially increased the haemoglobin concentration in our cases in spite of their reduced reticulocyte counts.

Risky occupational behavior such as siphoning of fuel into the mouth by automechanics and not wearing nose masks (by automobile sprayers) in the work place was very prevalent in our study population. This is not surprising considering that majority of the cases (automobile sprayers and automechanics) had never received any training in occupational safety. This prevalent practice of aspiration of petrochemicals has previously been reported by others [22, 23]. Although our study revealed suppressed haematopoietic challenges in automobile workers, the impact of our study is limited by our inability to estimate the heavy metal levels in the serum of both our cases and controls. This would have broadened the scope of our findings considerably.

\section{Conclusions}

There is reduced haematopoietic output in automobile mechanics and automobile sprayers. There is also lack of adherence to occupational safety principles which requires urgent attention if long term effects of petrochemical exposures are to be prevented.

\author{
Abbreviations \\ RBC: Red cell count \\ WBC: White blood cell \\ MCV: Mean cell volume \\ $\mathrm{MCH}$ : Mean cell haemoglobin
}

MCHC: Mean cell haemoglobin concentration

RDW: Red cell distribution width.

\section{Ethical Approval}

All protocols for this study were reviewed by the Institutional Review Board (IRB), University of Cape Coast, and ethical clearance number was issued: UCCIRB/CHAS/2015/97.

\section{Consent}

Informed consent (written) from the enrolled participants was given before venous blood samples were taken.

\section{Disclosure}

The research was self-funded by Patrick Adu, Aaron Awuah, Richard Pobee, and Paul B. Asiamah.

\section{Conflicts of Interest}

The authors declare that they have no conflicts of interest.

\section{Authors' Contributions}

Patrick Adu conceived and designed the research; Sampson Gyabaa, Aaron Awuah, Richard Pobee, Paul B. Asiamah, and Festus Amoani were involved in sampling, experimental work, data collection, and literature search. Patrick Adu analyzed and interpreted the data. Festus Amoani wrote the initial draft which was revised by Patrick Adu. All authors read and approved the manuscript.

\section{Acknowledgments}

The authors are grateful to the staff of Ewim Polyclinic Laboratory, particularly for their support in the course of this research.

\section{Supplementary Materials}

Supplementary 1. Table S1: comparison of mean haematological parameters between mechanics and sprayers. Respective haematological variables of mechanics and automobile sprayers were compared using Mann-Whitney test. Data are presented as mean \pm standard deviation at 95\% CI (confidence interval); statistical significance was set at $p<$ 0.05 .

Supplementary 2. Table S2: comparison of mean haematological parameters of sprayers with varying years of work experience. Haematological variables were compared among automobile sprayers based on years at work. Data are presented as mean \pm standard deviation at 95\% CI (confidence interval). All statistical comparisons were undertaken using KruskalWallis test with Dunn's post hoc multiple comparison test.

Supplementary 3. Table S3: comparison of mean haematological parameters of mechanics based on years of work experience. Haematological variables were compared among automobile mechanics based on years at work. Data are 
presented as mean \pm standard deviation at 95\% CI (confidence interval). All statistical comparisons were undertaken using Kruskal-Wallis test with Dunn's post hoc multiple comparison test.

\section{References}

[1] A. Kamal and A. Rashid, "Benzene exposure among autorepair workers from workplace ambience: A pioneer study from Pakistan," International Journal of Occupational Medicine and Environmental Health, vol. 27, no. 5, pp. 830-839, 2014.

[2] F. N. Oguwike, E. S, O. D.P.M, and O. C.C, "Effects of Petroleum and Crude Oil in the Gastrointestinal System of Male Roadside Mechanics in Enugu State, Nigeria," IOSR Journal of Dental and Medical Sciences, vol. 13, no. 10, pp. 29-31, 2014.

[3] A. Akintonwa, B. A. Ojo, P. Emeka, H. Coker, and O. Sofola, "Effect of Chronic Exposure to petroleum products on some Hematological and Biochemical parameters," Nigerian Quarterly Journal of Hospital Medicine, vol. 15, no. 2, pp. 77-82, 2008.

[4] A. O. Ajugwo, T. C. Adias, K. Aghatise, J. K. Fadairo, and C. U. Nyenke, "Reduced Haematological Indices in Auto-Mechanics and Fuel Attendants in Elele Nigeria," American Journal of Medical and Biological Research, vol. 2, no. 1, pp. 1-4, 2014.

[5] B. Vitayavirasuk, S. Junhom, and P. Tantisaeranee, "Exposure to lead, cadmium and chromium among spray painters in automobile body repair shops," Journal of Occupational Health, vol. 47, no. 6, pp. 518-522, 2005.

[6] M. Aleemuddin, M. G. Babu, M. L. Manjunath, and S. S. Quadri, "Effect of chronic inhalation of petroleum products on hematological parameters," International Journal of Current Research and Academic Review, vol. 3, no. 4, pp. 196-201, 2015.

[7] G. Flora, D. Gupta, and A. Tiwari, "Toxicity of lead: a review with recent updates," Interdisciplinary Toxicology, vol. 5, no. 2, pp. 47-58, 2012.

[8] S. A. Quadri, A. N. Qadri, M. E. Hahn, K. K. Mann, and D. H. Sherr, "The bioflavonoid galangin blocks aryl hydrocarbon receptor activation and polycyclic aromatic hydrocarboninduced pre-B cell apoptosis," Molecular Pharmacology, vol. 58, no. 3, pp. 515-525, 2000.

[9] R. I. Handin, S. E. Lux, and T. P. Stossel, Principles and Practice of Haematology, vol. 1, Lippincott Williams \& Wilkins, 2003.

[10] R. S. Riley, J. M. Ben-Ezra, R. Goel, and A. Tidwell, "Reticulocytes and reticulocyte enumeration," Journal of Clinical Laboratory Analysis, vol. 15, no. 5, pp. 267-294, 2001.

[11] M. Cheesbrough, District Laboratory Practice in Tropical Countries, Cambridge University Press, Cambridge, UK, 2nd edition, 2006.

[12] B. H. Estridge, A. P. Reynolds, and N. J. Walters, Basic Medical Laboratory Techniques, Delmar Thomson Learning, 4th edition, 2000.

[13] A. Kamal and R. N. Malik, "Hematological Evidence of Occupational Exposure to Chemicals and Other Factors among AutoRepair Workers in Rawalpindi, Pakistan," Osong Public Health and Research Perspectives, vol. 3, no. 4, pp. 229-238, 2012.

[14] C. G. Hunter, "Aromatic solvents," Annals of Occupational Hygiene, vol. 9, no. 4, pp. 191-198, 1966.

[15] P. Hotz and R. R. Lauwerys, "Hematopoietic and lymphatic malignancies in vehicle mechanics," Critical Reviews in Toxicology, vol. 27, no. 5, pp. 443-494, 1997.

[16] J.-Y. Hong, "The effect of preoperative ketorolac on WBC response and pain in laparoscopic surgery for endometriosis," Yonsei Medical Journal, vol. 46, no. 6, pp. 812-817, 2005.
[17] S. G. Christian, I. Elekima, A. U. Obisike, and C. P. Aleru, "Effect of Petroleum on Haematological Parameters and Lead Level in Fuel Attendants in Port Harcourt, Nigeria," International Journal of Science and Research (IJSR), vol. 5, no. 3, pp. 280-283, 2016.

[18] R. J. Sherwood and F. W. G. Carter, "The measurement of occupational exposure to benzene vapour," Annals of Occupational Hygiene, vol. 13, no. 2, pp. 125-146, 1970.

[19] K. V. Patel, L. Ferrucci, W. B. Ershler, D. L. Longo, and J. M. Gurainik, "Red blood cell distribution width and the risk of death in middle-aged and older adults," JAMA Internal Medicine, vol. 169, no. 5, pp. 515-523, 2009.

[20] T. S. Perlstein, J. Weuve, M. A. Pfeffer, and J. A. Beckman, "Red blood cell distribution width and mortality risk in a community-based prospective cohort," JAMA Internal Medicine, vol. 169, no. 6, pp. 588-594, 2009.

[21] P.-C. Chen, F.-C. Sung, K.-L. Chien, H.-C. Hsu, T.-C. Su, and Y.-T. Lee, "Red blood cell distribution width and risk of cardiovascular events and mortality in a community cohort in Taiwan," American Journal of Epidemiology, vol. 171, no. 2, pp. 214-220, 2010.

[22] L. Wallace, "Environmental exposure to benzene: An update," Environmental Health Perspectives, vol. 104, no. 6, pp. 1129-1136, 1996.

[23] N. E. Udonwa, E. K. Uko, B. M. Ikpeme, I. A. Ibanga, and B. O. Okon, "Exposure of petrol station attendants and auto mechanics to premium motor sprit fumes in Calabar, Nigeria," Journal of Environmental and Public Health, vol. 2009, Article ID 281876, 2009. 


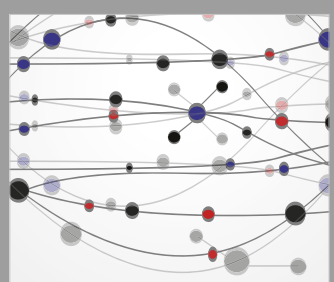

The Scientific World Journal
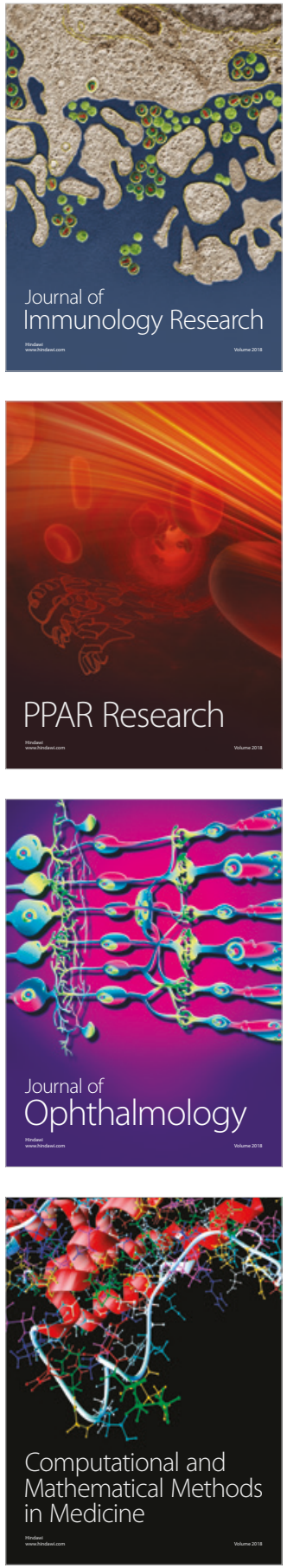

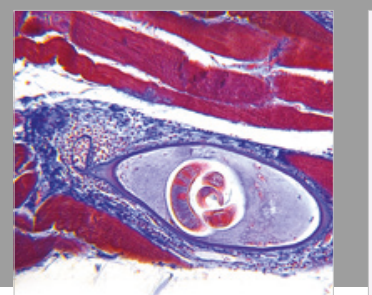

Gastroenterology Research and Practice

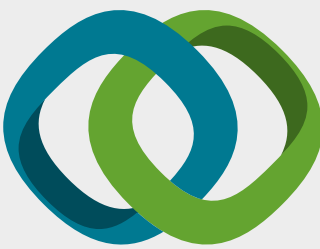

\section{Hindawi}

Submit your manuscripts at

www.hindawi.com
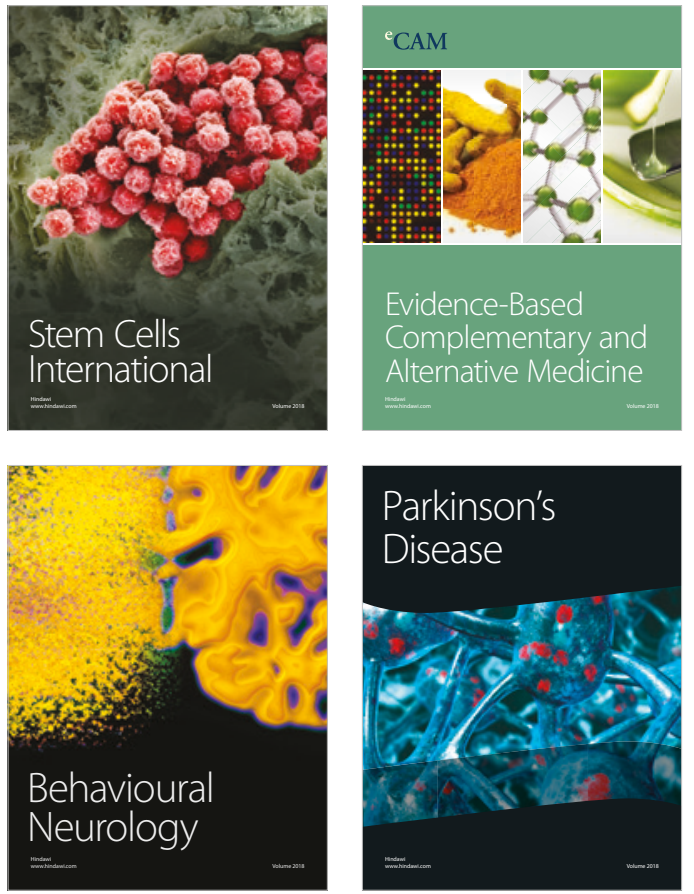

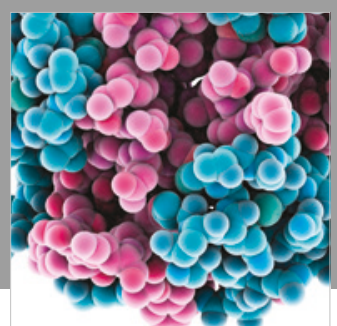

ournal of

Diabetes Research

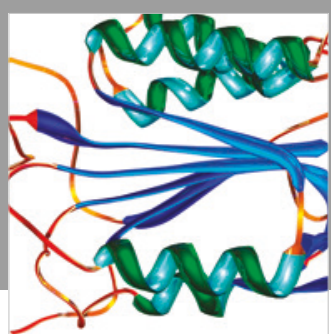

Disease Markers
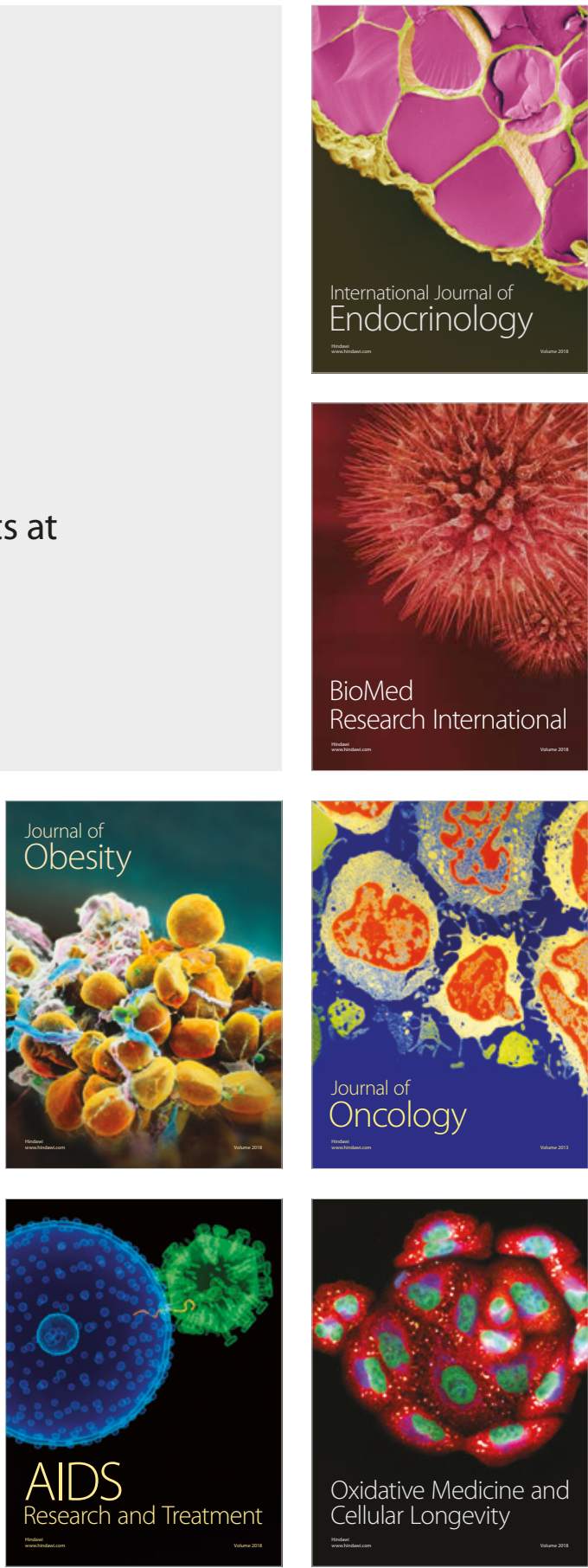